\title{
DESENVOLVIMENTO DE NOVOS PRODUTOS ALIMENTÍCIOS: CHOCOLATE SEM LACTOSE À BASE DE MACADÂMIA
}

\author{
C. F. SILVA ${ }^{1}$, R. F. NASCIMENTO ${ }^{1}$ e L. S. ARRIECHE ${ }^{2}$ \\ ${ }^{1}$ Universidade Federal do Espírito Santo, Curso de Engenharia Química \\ ${ }^{2}$ Universidade Federal do Espírito Santo, Departamento de Engenharias e Tecnologia \\ E-mail para contato: carolferron@ hotmail.com
}

\begin{abstract}
RESUMO - Frente a um mercado globalizado e competitivo, a indústria do cacau vem se aprimorando a fim de criar os mais variados sabores de chocolates. $\mathrm{O}$ objetivo deste trabalho foi desenvolver um chocolate, sem lactose, utilizando macadâmia ao invés do leite de soja, comumente adicionado em formulações especiais. Para a elaboração dos protótipos foram testadas fórmulas desenvolvidas através de programação linear, a fim de otimizar a composição de macronutrientes mais próxima ao padrão, o chocolate de soja. Em seguida foram realizados testes sensoriais com 22 pessoas treinadas para escolher a amostra mais semelhante ao padrão. A etapa seguinte foi a análise estatística dos resultados, obtidos através da análise descritiva quantitativa de atributos de textura, tais como dureza, adesividade e granulosidade. A amostra com $16,57 \%$ de macadâmia apresentou maior número de atributos sem diferença significativa da amostra padrão e um índice de aceitação de $62,5 \%$.
\end{abstract}

\section{INTRODUÇÃO}

Atualmente as indústrias alimentícias enfrentam uma realidade econômica de intensa competitividade no mercado global. O desenvolvimento de novos produtos é um fator fundamental para o crescimento e sobrevivência de uma indústria. Seu objetivo é trazer um novo produto ao mercado com a menor quantidade de incerteza possível (Beckley et al., 2007). Novos produtos podem ser desenvolvidos de duas maneiras: através de aquisições ou através do desenvolvimento a partir dos departamentos de pesquisa e desenvolvimento (P\&D); através da contratação de pesquisadores independentes ou então através da contratação de empresas especializadas nesse setor (Alves et al., 2000). Dentre as indústrias com maior número de novos produtos lançados a cada ano destaca-se a indústria de chocolate, que crescerá $29,7 \%$ até 2015 (Euromonitor, 2012, p. 3, apud Barry Callebaut).

Os tipos preferidos de chocolate variam de um país para outro. O sabor do chocolate é parcialmente determinado pela composição química do produto, dependendo da liberação dos compostos aromáticos; enquanto a textura é resultado da maneira como o material se funde e quebra na boca. Alguns produtos têm aromas específicos, gerados pelas mudanças frequentes 


\section{9 a 22 de outubro de 2014 \\ Florianópolis/SC}

ocasionadas pelas variações no processo, acidez e temperatura, implicando em variações de aroma e sabor no produto. A composição exata do chocolate varia em todo o mundo devido aos diferentes gostos e legislações, que determinam as porcentagens de cacau e sólidos do leite adicionais, quantidade e tipos de gorduras vegetais permitidas (Richter e Lannes, 2007).

Além de estudos para aperfeiçoamento do processo, muitos esforços foram feitos nos últimos anos para criar os mais diferentes tipos e sabores de chocolates, visando sempre à permanência e aumento da presença no mercado global. Uma das alternativas para a formulação de novos chocolates destinados aos públicos especiais com produtos regionais é a utilização da macadâmia. Existe atualmente uma larga cultura da noz macadâmia no estado do Espírito Santo representa $31 \%$ da produção do Brasil, ficando atrás apenas do estado de São Paulo, com 33\% podendo ser uma alternativa para a produção regional de chocolate para os alérgicos a lactose e para o público em geral, por ser um produto funcional (Triade Comunicação, 2010).

A macadâmia é uma noz originada da Austrália, com sabor diferenciado e possui óleos naturais, carboidratos, proteínas, fibras, minerais como potássio, fósforo, magnésio, cálcio e vitaminas. Além disso, traz benefícios por ser rica em ômega 3, ácidos graxos e antioxidantes, responsáveis por retardar o envelhecimento, e vem conquistando destaque nos cenários nacional e capixaba, que possui um clima favorável para o cultivo e um intenso controle de qualidade da amêndoa triturada (Triade Comunicação, 2010). Uma provável opção de chocolate para pessoas com dieta restritiva e/ou intolerantes a lactose poderia ser obtida através da utilização da macadâmia como substituto do leite em pó ou de soja, uma vez que adicionaria valor nutritivo ao chocolate, devido às suas vitaminas, minerais, ácidos graxos e antioxidantes, sendo um produto livre de componentes de origem animal.

Neste sentido, o objetivo deste trabalho foi desenvolver um chocolate livre de lactose, sem nenhum ingrediente de origem animal e à base de macadâmia, com características sensoriais e tecnológicas viáveis para a sua produção, bem como benefícios nutricionais diferenciados em relação aos chocolates tradicionais.

\section{METODOLOGIA}

\subsection{Treinamento da Equipe de Analistas Sensoriais}

Foram realizados testes sensoriais com 30 voluntários, com faixa etária de 18 a 50 anos, objetivando-se selecionar um número mínimo de 10 julgadores com acuidade sensorial eficaz e com resultados superiores a $80 \%$ de acertos. Os testes foram realizados com 4 provadores por vez, em uma sala com aproximadamente $70 \mathrm{~m}^{2}$, posicionados em cantos diagonalmente opostos. Os formulários continham esclarecimentos a respeito da pesquisa, características e preferências pessoais, e os três testes (triangular, ordenação de dureza e ordenação de sabor amargo).

\subsection{Desenvolvimento das Formulações}

Foram determinadas formulações que atendessem às mesmas características (carboidratos, 
proteínas, gorduras, fibras e água) do produto padrão, um chocolate com extrato de soja. Seus ingredientes básicos são açúcar, manteiga de cacau, massa de cacau, extrato e lecitina de soja.

Depois, dois procedimentos de mistura foram seguidos: (1) sobre manta de aquecimento, em banho-maria, todas as quantidades determinadas pela programação linear foram colocadas juntas em recipiente de inox e, com mixagem constante, esperava-se até que atingisse a temperatura de $70 \pm 3{ }^{\circ} \mathrm{C}$; e (2) em procedimento de aquecimento como em (1), foi adicionada metade da massa de manteiga de cacau, os demais ingredientes, a outra metade da manteiga e o açúcar, nesta ordem, esperou-se atingir também a temperatura de $70 \pm 3{ }^{\circ} \mathrm{C}$.

$\mathrm{Na}$ temperagem, ciclos de resfriamento e aquecimento estabilizam a formação de cristais de manteiga e açúcar. $\mathrm{O}$ resfriamento foi feito em pedra de granito, até que a temperatura atingisse em torno de $28^{\circ} \mathrm{C}$. Para não haver contato com o produto, as temperaturas foram medidas com temômetro infravermelho digital com precisão de $\pm 2,5 \%$ da leitura.

Com relação à função objetivo adotada, a programação linear permitiu delinear uma região viável, respeitando as restrições relacionadas à legislação e o valor nutricional igual ao padrão. Algumas formulações desta região foram descartadas em função de variações nos procedimentos de temperagem e moldagem e observação consensual entre os membros da pesquisa.

\subsection{Análise Sensorial das Amostras}

Para a determinação do melhor chocolate entre as duas amostras selecionadas da região viável, foram realizados testes de textura não gustativos de Estimativa de Magnitude, com Escala Não Estruturada de $9 \mathrm{~cm}$ e escala hedônica de atratividade visual. Utilizou-se uma amostra de 6 g do chocolate Chocosoy Crispies ${ }^{\circledR}$ como padrão, e uma amostra de $30 \mathrm{~g}$ de cada formulação. As amostras foram testadas por 15 provadores previamente treinados. Os dados foram tratados no software Microsoft@ Office Excel 2007.

\subsection{Análise Estatística}

A escolha de dois tipos diferentes de testes para medir atributos não gustativos foi feita porque estes estão entre os mais adequados para o desenvolvimento de novos produtos, sem a utilização de protótipo (IFT/SED, 1981).

Testes de Atratividade - Escala Hedônica de Nove Pontos: Foram utilizadas escalas de nove pontos, em que cada ponto possuía um valor atribuído de -4 a 4 . Para cada um dos atributos testados para cada amostra foram obtidos os valores de média amostral, desvio padrão amostral, média total de atratividade das amostras e seu desvio padrão.

Testes de Estimativa de Magnitude de Escala de Não Estruturada: Foi utilizada escala não estruturada medindo $10 \mathrm{~cm}$ da marcação de mínimo até a de máximo e $1 \mathrm{~cm}$ além dessas marcações, que correspondem a -6 e 6 , totalizando $12 \mathrm{~cm}$. Para a obtenção do valor a ser utilizado para a análise estatística foi realizada uma conversão de um intervalo medido com uma 
régua milimetrada para um número que variava numa escala de -6 a 6 , com precisão de 0,1 . Cada resposta foi interpretada e traduzida para um número neste intervalo, para posterior análise.

Para cada um dos atributos testados em cada amostra, foram obtidos os valores de média amostral e desvio padrão amostral. A análise estatística dos resultados foi realizada através do teste $\mathrm{t}$ de Student dependente, com nível de significância de 5\% e número de respostas igual a 15. Os resultados foram tratados no software SOFA Statistics®.

\subsection{Teste de Aceitação do Produto}

O produto selecionado na etapa anterior foi testado com 24 pessoas não treinadas, numa faixa etária de 12 a 70 anos, durante o período da noite, em ambiente sem ar condicionado, em mesas separadas por um raio de $4 \mathrm{~m}$. Foi utilizado o teste de escala hedônica de 9 pontos, para que analisassem uma amostra de aproximadamente $15 \mathrm{~g}$ de chocolate.

\section{RESULTADOS E DISCUSSÕES}

\subsection{Seleção das Formulações}

Após o preparo de todas as formulações, foram selecionadas as que apresentaram melhor desempenho com relação à cor, brilho, dureza, odor e textura. Observou-se que as preparadas com líquor de cacau aproximavam-se mais do chocolate comercial, pois apresentaram brilho característico e facilidade de desmoldar, devido ao líquor de cacau ser mais rico em gordura do que o cacau em pó. Já as formulações realizadas utilizando o cacau em pó não apresentaram uma consistência adequada.

O açúcar cristal moído em processador comercial, apesar de não estar na granulometria desejada, possibilitou um sabor mais próximo ao chocolate padrão, sendo, portanto a melhor escolha entre os testados. Com relação à macadâmia observou-se que as formulações com quantidades entre 15 e $20 \%$, apesar de derreterem com maior facilidade, devido ao alto teor de gordura presente na noz, apresentaram textura e brilho próximos ao do chocolate comercial. Em contrapartida, as formulações com massa de macadâmia de até $10 \%$ da massa total não apresentaram uma massa com a viscosidade apropriada para a conchagem.

Das formulações preparadas com líquor de cacau, apenas duas foram escolhidas, uma vez que das outras amostras, algumas possuíam sabor e odor desagradáveis, pouco brilho e alto grau de derretimento. Portanto as formulações escolhidas podem ser observadas na Tabela 1.

Tabela 1 - Composição das formulações escolhidas para os testes sensoriais e análise estatística

\begin{tabular}{ccc}
\hline Composição (base de 100 g) & Formulação 1 (em g) & Formulação 2 (em g) \\
\hline Açúcar cristal moído & 46 & 47,0 \\
Líquor de cacau & 29,9 & 16,1 \\
Manteiga de cacau & 5,1 & 20,2 \\
Lecitina de soja & 0,1 & 0,128 \\
Macadâmia & 18,9 & 16,6 \\
\hline
\end{tabular}




\subsection{Análise Estatística dos Testes Sensoriais das Amostras Escolhidas}

Os resultados obtidos nos testes de atratividade podem ser conferidos na Tabela 2.

Tabela 2 - Análise estatística para as respostas dos testes de atratividade

\begin{tabular}{ccccccc}
\hline Atributos & \multicolumn{2}{c}{ Amostra padrão } & \multicolumn{2}{c}{ Amostra Teste 1 } & \multicolumn{2}{c}{ Amostra Teste 2 } \\
\cline { 2 - 7 } & Média & $\begin{array}{c}\text { Desvio padrão } \\
\text { amostral }\end{array}$ & Média & $\begin{array}{c}\text { Desvio padrão } \\
\text { amostral }\end{array}$ & $\begin{array}{c}\text { Média } \\
\text { Desvio padrão } \\
\text { amostral }\end{array}$ \\
\hline $\begin{array}{c}\text { Cor } \\
\text { Brilho }\end{array}$ & 3,13 & 0,743 & 2,27 & 1,1 & 1,21 & 1,2 \\
Textura ao Toque & 2 & 1 & 1,8 & 1,21 & 1,03 \\
Forma & 2,4 & 1,18 & 0,933 & 1,49 & 1,07 & 1,41 \\
Odor & 2,4 & 1,18 & 2,47 & 1,06 & 1,73 & 1,33 \\
Homogeneidade & 3,27 & 0,704 & 0,733 & 2,09 & 0,933 & $\mathbf{1 , 1 2}$ \\
Média & 2,67 & 1,18 & $\mathbf{1 , 6 3}$ & $\mathbf{1 , 6 1}$ & & $\mathbf{1 , 5 9}$ \\
\hline
\end{tabular}

A amostra teste 1 apresentou maior atratividade que a amostra teste 2 para os parâmetros cor, brilho e odor. Entretanto, a amostra teste 2 obteve melhor desempenho que a 1 nos aspectos textura ao toque, forma e homogeneidade. As amostras teste diferiram significativamente entre si apenas com relação aos parâmetros de forma e odor.

Observa-se que os valores de desvio padrão possuem ordem de grandeza próxima ao da média, devido ao fato de as variações no estado das amostras geradas por variações de temperatura durante os testes. Essas polarizações ocorreram uma vez que o teste foi realizado durante o dia em uma sala que não possuía ar condicionado, ocasionando alteração de forma, brilho e textura, por exemplo, aumentando a variabilidade nos resultados obtidos.

A Figura 1 ilustra a proximidade das amostras teste em relação à amostra padrão.

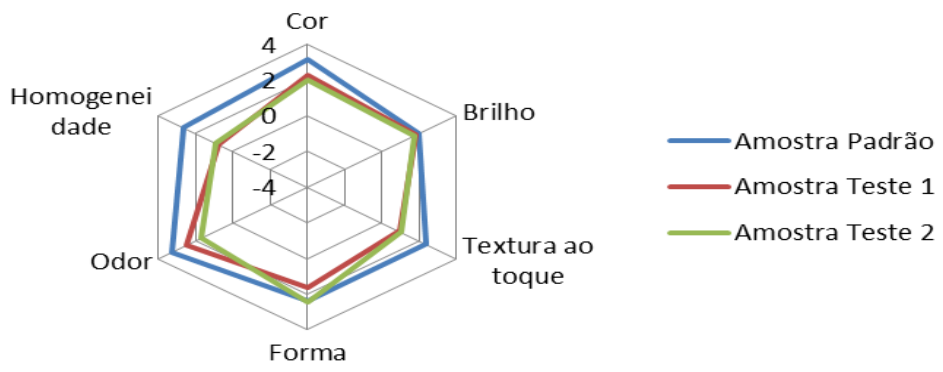

Figura 1 - Gráfico aranha dos resultados obtidos no teste de escala hedônica.

Os resultados das amostras teste para todos os atributos analisados são muito semelhantes e diferem da amostra padrão, salvo para os parâmetros de brilho para ambas as amostras teste, e forma para a amostra teste 2. Através dos resultados obtidos nos testes de atratividade não é possível indicar qual das amostras teste é superior a outra, uma vez que a margem de diferença no resultado final entre ambas é muito pequena, inferior a $2 \%$. Os resultados obtidos nesses testes podem ser conferidos na Tabela 6. 
Tabela 6 - Análise estatística para as respostas dos testes de estimativa de magnitude excluindose as respostas afastadas da média

\begin{tabular}{ccccccc}
\hline Atributos & \multicolumn{2}{c}{ Amostra padrão } & \multicolumn{2}{c}{ Amostra Teste 1 } & \multicolumn{2}{c}{ Amostra Teste 2 } \\
\cline { 2 - 7 } & Média & $\begin{array}{c}\text { Desvio padrão } \\
\text { amostral }\end{array}$ & Média & $\begin{array}{c}\text { Desvio padrão } \\
\text { amostral }\end{array}$ & $\begin{array}{c}\text { Média } \\
\text { Desvio padrão } \\
\text { amostral }\end{array}$ \\
$\begin{array}{c}\text { Cor } \\
\text { Dureza }\end{array}$ & 0,93 & 0,726 & 3,46 & 0,612 & 1,76 & 1,04 \\
Fraturabilidade & 3,28 & 0,803 & $-3,64$ & 0,864 & $-2,94$ & 1,66 \\
Grau de Derretimento & 3,45 & 0,798 & $-2,55$ & 0,856 & $-2,26$ & 1,26 \\
Adesividade & 5,03 & 0,9 & 0,45 & 1,09 & $-0,2$ & 1,40 \\
Espalhabilidade & $-2,76$ & 1,59 & $-0,59$ & 1,89 & $-1,25$ & 1,65 \\
\hline
\end{tabular}

Os valores de desvio padrão diminuíram e apenas o parâmetro de espalhabilidade da amostra padrão ainda possui valor próximo a ordem de grandeza da média, sendo um resultado mais confiável, exceto para este parâmetro. Pela Figura 2, há uma diferença na magnitude dos parâmetros dureza, fraturabilidade e grau de derretimento entre a amostra padrão e as amostras teste 1 e 2, devido a limitações ocorridas durante o processo de temperagem, provenientes da instabilidade dos cristais remanescentes vindos das falhas de controle de temperatura.

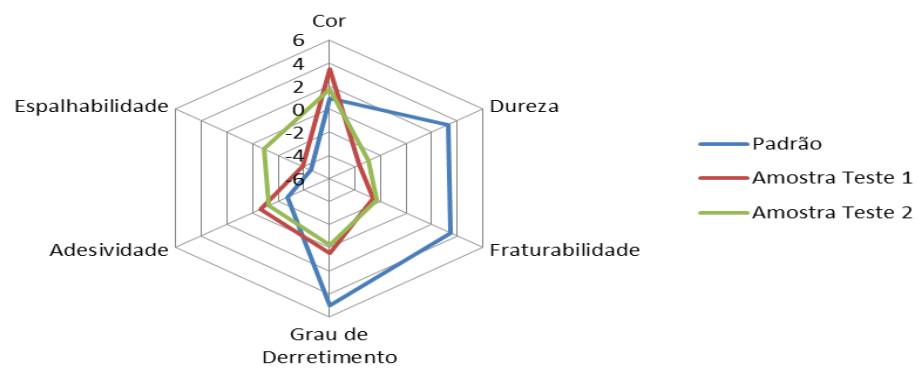

Figura 2 - Gráfico aranha dos resultados obtidos no este de estimativa de magnitude excluindose as respostas afastadas da média.

A escolha do processo de temperagem convencional foi fundamental para que houvesse problemas nesta etapa, já que a amostra foi resfriada e depois novamente aquecida. Atualmente as indústrias não reaquecem o chocolate, parando a têmpera no resfriamento, a cerca de $29^{\circ} \mathrm{C}$.

Uma vez excluídos os pontos afastados da média, testou-se as três amostras a fim de verificar diferenças entre elas através da análise do teste t de Student pareado, para um nível de $5 \%$ de significância, mostrados nas Tabelas 7,8 e 9.

Tabela 7 - Resultados do teste t de Student pareado da amostra padrão e amostra teste 1

\begin{tabular}{ccccccc}
\hline & \multicolumn{7}{c}{ Amostra Padrão e Amostra Teste 1 } \\
\hline Resultados & Cor & Dureza & Fraturabilidade & Grau de Derretimento & Adesividade & Espalhabilidade \\
\hline $\mathbf{M}_{\text {dif }}$ & 2,82 & $-6,39$ & $-5,31$ & $-4,26$ & 1,69 & 0,167 \\
$\mathbf{S}_{\text {dif }}$ & 1,28 & 2,09 & 2,01 & 2,01 & 2,80 & 2,72 \\
SE & 0,331 & 0,540 & 0,519 & 0,519 & 0,724 & 0,703 \\
$\mathbf{T}$ & 8,53 & $-11,8$ & $-8,20$ & $-8,20$ & 2,34 & 0,237 \\
Hipótese Verdadeira & $\mathrm{H}_{1}$ & $\mathrm{H}_{1}$ & $\mathrm{H}_{1}$ & $\mathrm{H}_{1}$ & $\mathrm{H}_{1}$ & $\mathrm{H}_{0}$ \\
\hline
\end{tabular}


Pela análise da Tabela 7 nota-se que a amostra padrão e a amostra teste 1 só se assemelham no atributo espalhabilidade. $\mathrm{O}$ erro padrão foi insignificante para todos os atributos testados, mostrando uma baixa variabilidade populacional.

Tabela 8 - Resultados do teste t de Student pareado da amostra padrão e amostra teste 2

\begin{tabular}{ccccccc}
\hline & \multicolumn{7}{c}{ Amostra Padrão e Amostra Teste 2 } \\
\hline Resultados & Cor & Dureza & Fraturabilidade & Grau de Derretimento & Adesividade & Espalhabilidade \\
\hline $\mathbf{M}_{\text {dif }}$ & 0,467 & $-5,74$ & $-5,31$ & $-4,66$ & 1,08 & 2,04 \\
$\mathbf{S}_{\text {dif }}$ & 1,74 & 2,45 & 1,77 & 2,62 & 3,51 & 4,03 \\
$\mathbf{S E}$ & 0,449 & 0,633 & 0,456 & 0,676 & 0,907 & 1,04 \\
$\mathbf{T}$ & 1,04 & $-9,06$ & $-11,6$ & $-6,89$ & 1,19 & 1,96 \\
Hipótese Verdadeira & $\mathrm{H}_{0}$ & $\mathrm{H}_{1}$ & $\mathrm{H}_{1}$ & $\mathrm{H}_{1}$ & $\mathrm{H}_{0}$ & $\mathrm{H}_{0}$ \\
\hline
\end{tabular}

Em contrapartida, pela análise da Tabela 8, percebe-se que não há diferença significativa com relação aos parâmetros cor, adesividade e espalhabilidade. $\mathrm{O}$ erro padrão para as diferenças entre as amostras analisadas foi insignificante para todos os atributos testados, exceto espalhabilidade. Não havendo, então, variabilidade populacional para o resultado deste atributo.

Tabela 9 - Resultados do teste t de Student pareado das amostras teste 1 e 2

\begin{tabular}{ccccccc}
\hline & \multicolumn{7}{c}{ Amostras Teste 1 e 2 } \\
\hline Resultados & Cor & Dureza & Fraturabilidade & Grau de Derretimento & Adesividade & Espalhabilidade \\
\hline $\mathbf{M}_{\text {dif }}$ & $-2,35$ & 0,647 & 0,200 & $-0,400$ & $-0,613$ & 1,87 \\
$\mathbf{S}_{\text {dif }}$ & 1,52 & 1,56 & 1,40 & 2,06 & 1,87 & 2,02 \\
$\mathbf{S E}$ & 0,392 & 0,404 & 0,361 & 0,531 & 0,483 & 0,522 \\
$\mathbf{T}$ & $-6,01$ & 1,60 & 0,555 & $-0,753$ & $-1,27$ & 3,59 \\
Hipótese Verdadeira & $\mathrm{H}_{1}$ & $\mathrm{H}_{0}$ & $\mathrm{H}_{0}$ & $\mathrm{H}_{0}$ & $\mathrm{H}_{0}$ & $\mathrm{H}_{1}$ \\
\hline
\end{tabular}

Pela análise da Tabela 9, comprovou-se que as amostras teste diferem entre si somente em dois atributos: cor e espalhabilidade. $\mathrm{O}$ erro padrão para as diferenças entre as amostras teste foi insignificante para todos os atributos testados.

\subsection{Teste de Aceitação}

Nesta etapa, feito com a amostra teste 2, foi utilizada a escala hedônica de nove pontos, em que cada resposta correspondia a um valor, que variava de -4 a 4 . A resposta foi convertida para um valor dentro da escala e os dados tratados a fim de verificar o grau de aceitação da amostra testada, sendo a média das respostas igual a 2,5 com desvio padrão de 1,29. Observou-se que a frequência de consumo de chocolate dos voluntários foi superior a uma vez por semana.

Uma vez que o valor 2,5 encontra-se mais próximo ao valor 3, constata-se que a maioria dos consumidores gostou muito da amostra testada. Considerando o desvio padrão, a resposta à aceitação do produto final variou de gostei ligeiramente a gostei extremamente.

Segundo o teste estatístico de Shapiro-Wilk W (SW-W) é possível afirmar que os dados seguem uma distribuição normal uma vez que a estatística SW-W não é significativa, inferior a 1, implicando na aceitação da hipótese que os dados seguem uma distribuição normal. Confirmado pelo valor p que é inferior ao grau de significância de $5 \%$. 


\section{CONCLUSÃO}

Com relação ao treinamento da equipe realizado, os bons resultados apresentados pelos selecionados para a equipe de analistas sensoriais facilitou a obtenção de resultados confiáveis nas etapas posteriores, sendo fundamentais para a confiabilidade dos resultados obtidos.

Com relação ao desenvolvimento das formulações, conclui-se que o chocolate padrão não correspondia a um chocolate igual ao que foi desenvolvido, já que o padrão utilizado era à base de soja e não macadâmia. A diversidade de formulações permitiu desenvolver um protótipo de boa aceitação, determinada através do teste de atratividade, obtendo uma nota final de 2,5, que mais se aproxima do valor 3 que corresponde a resposta gostei muito na escala utilizada.

O resultado da atratividade da amostra selecionada foi satisfatório. Verificou-se também que a amostra teste 2 apresentou o melhor desempenho global dentre as amostras testadas, obtendo um desempenho superior de $1,36 \%$ quando comparada a amostra teste 1. A amostra teste 2 não apresentou diferença significativa em relação à amostra padrão para os parâmetros cor, adesividade e espalhabilidade, enquanto a amostra teste 1 diferiu significativamente do padrão em relação a cinco dos seis atributos testados, exceto o parâmetro espalhabilidade.

Pode-se afirmar que sensorialmente, o chocolate à base de macadâmia é atrativo, mas ainda requer estudos sobre o perfil dos consumidores, mercado, uma estratégia de marketing e análise comercial, a fim de certificar se ele deve ou não ser comercializado.

\section{REFERÊNCIAS BIBLIOGRÁFICAS}

ALVES, F.V.; ARRIECHE, L. S.; BONATO, S. R. Desenvolvimento de um produto alimentício, tipo baby food, com base na farinha de arroz integral pré-gelatinizada. 2000. $152 \mathrm{f}$. Monografia (Graduação em Engenharia de Alimentos) - Departamento de Química, Fundação Universidade Federal do Rio Grande, Rio Grande.

BARRY CALLEBAUT. Journal: The amazing world of chocolate. Zurique: Barry Callebaut AG. [s.d.].

BECKLEY, J. H.; FOLEY, M. M.; TOPP, E. J.; HUANG, J. C.; PRINYAWIWATKUL, W. Accelerating new food product design and development. Ames: Blackwell Publishing Professional, 2007.

IFT/SED. Sensory evaluation guide for testing food and beverage products. Food Technology. v. 35 (11), pages 550-559, Nov. 1981.

RICHTER, M; LANNES, S. C. S. Ingredientes usados na indústria de chocolates. Rev. Bras. Ciênc. Farmac., São Paulo, v. 43, n. 3, set. 2007.

TRIADE COMUNICAÇÃO. Macadâmia ganha mercado e produtores investem em controle de qualidade. Jornal Agrosoft, 11 maio 2010. 